\title{
Decarburization and Denitrogenization of Iron and Iron-Chromium Alloys by Plasma Jet of Hydrogen-Argon Gas Mixture*
}

\author{
By Kyojiro KANEKO,** Nobuo SANO** and Yukio MATSUSHITA**
}

\begin{abstract}
Synopsis
Trials to enhance decarburization and denitrogenization of molten ironchromium alloys were made by blowing plasma jet of hydrogen-argon gas mixtures onto the melt surface. The weight of melts was 1 to $3 \mathrm{~kg}$, the gas blowing rate $8 \mathrm{l} / \mathrm{min}$ and the electric power consumption 15 to $30 \mathrm{kVA}$. The final concentrations of carbon and nitrogen obtained were as follows: $\mathrm{C}<0.002 \%$ for $\mathrm{Fe}, 18-8$ stainless steel, $60 \% \mathrm{Cr}-\mathrm{Fe}$ alloy and $\mathrm{Cr}$; $\mathrm{N}=0.0015 \%$ for $\mathrm{Fe}$ and $\mathrm{N}=0.0065 \%$ for $25 \% \mathrm{Cr}-\mathrm{Fe}$ alloy, values that would satisfy the known requirement for good intergranular corrosion resistance and ductility for ferritic stainless steel of $\underline{\mathrm{C}}+\underline{\mathrm{N}}<100$ to 130 ppm.

By estimating the degree of dissociation of hydrogen in plasma jet at the metal interface, it was indicated that those hydrogen atoms in the plasma which were not thermally recombined into molecules should react with carbon and nitrogen in the molten metal. The mechanisms of decarburization and denitrogenization were also discussed.
\end{abstract}

\section{Introduction}

The use of high temperature plasma jet for practical refining of metals is receiving increasingly greater attentions. ${ }^{1-4)}$ The plasma jet which produces very high temperatures is advantageous for: (1) melting of not only refractory metals but ordinary iron and steel owing to its high efficiency of heat conduction to the melt, (2) acceleration of the reaction rate of refining at the high temperatures achieved, and (3) enhancement of the chemical reaction which could not otherwise occur.

The authors have interested themselves in the fundamental studies on the refining of iron-chromium alloys by plasma jet of hydrogen-argon gas mixtures impinged on the melt surface. The most important characteristics of the hydrogen plasma refining are that hydrogen atoms in the plasma which are still dissociated and not yet thermally recombined to molecules at the reaction interface of the melt should react with impurities such as carbon, nitrogen or oxygen in alloys, and that the loss of alloying elements caused by oxidation in the conventional oxidation refining process should be prevented thanks to the reducing atmosphere. On the other hand, the removal of carbon and nitrogen from iron-chromium alloys down to a very low level without loss of chromium is very important to ensure good intergranular corrosion resistance and ductility for ferritic stainless steels. ${ }^{5)}$

In the present paper, the results of decarburization and denitrogenization of iron-chromium alloys by plasma jet of hydrogen-argon gas mixtures and of decarburization of iron by plasma jet of carbondioxide-argon gas mixtures will be described and dis- cussed.

\section{Experimental Apparatus}

The reaction chamber for the plasma jet refining is shown schematically in Fig. 1. Argon was purified by flowing through calcium chrolide, then through a sponge titanium furnace heated at $850^{\circ} \mathrm{C}$, while hydrogen by a hydrogen diffusion unit of the silverparadium alloy. The cathode tip of the plasma torch was made of a tungsten rod of $5 \mathrm{~mm}$ diameter containing 1 to $2 \%$ thorium-oxide. The copper nozzle of the torch had a diameter of 5 to $6 \mathrm{~mm}$, and was exchangeable when damaged. The plasma jet was generated between the tungsten-cathode and the metal in crucible serving as the anode at a nominal output of the rectifier of $40 \mathrm{kVA}$. The pillar of plasma arc was stable in 6 to $8 \mathrm{~mm}$ diameter. A copper pipe of $10 \mathrm{~mm}$ diameter was attached to the bottom of the crucible for electric contact with the metal.

A magnesia crucible of $85 \mathrm{~mm}$ of inner diameter was used for a 2 to $3 \mathrm{~kg}$ melt, and a $65 \mathrm{~mm}$ one for $1 \mathrm{~kg}$. A pair of $30 \% \mathrm{Rh} / \mathrm{Pt}-6 \% \mathrm{Rh} / \mathrm{Pt}$ thermocouple was placed $5 \mathrm{~mm}$ inside of the crucible wall, so that the temperature indicated was approximately $150^{\circ} \mathrm{C}$

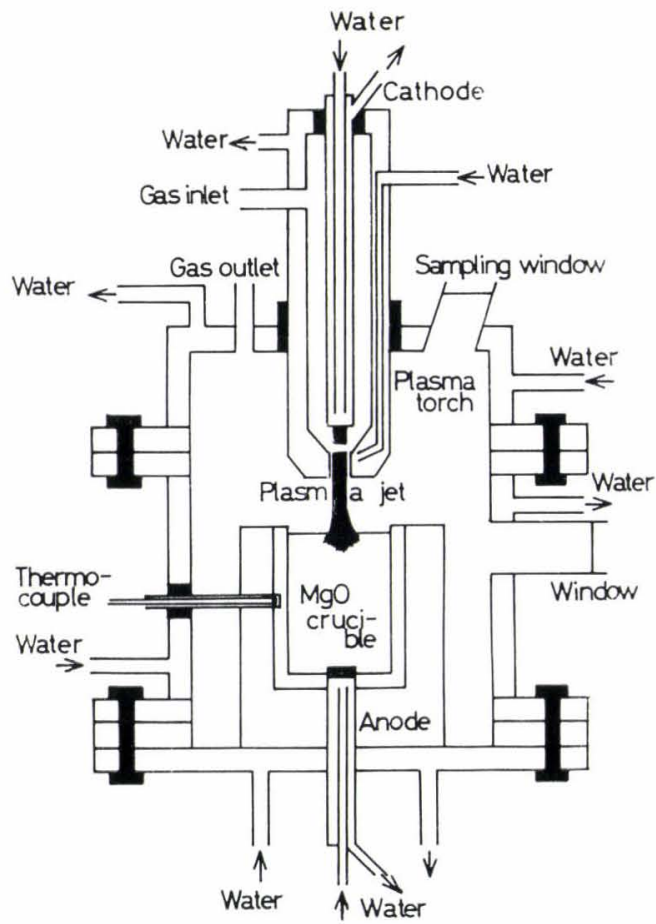

Fig. 1. Reaction chamber equipped with plasma torch and crucible

* Presented at the 2nd Japan-Germany Seminar, April, 1976 in Tokyo. Manuscript received April 22, 1976.

** Department of Metallurgy and Materials Science, Faculty of Engineering, The University of Tokyo, Hongo, Bunkyo-ku, Tokyo 113. 
lower than the true temperature of the melt.

When denitrogenization to yet lower levels was intended, a water-cooled copper mold was used because the final nitrogen contents refined in the magnesia crucible were limited to $50 \mathrm{ppm}$ for iron and $110 \mathrm{ppm}$ for $25 \%$ Cr ferroalloy, presumably owing to the air remaining in the stamped magnesia powders. In this case, however, only a melt pool of about $1.0 \mathrm{~kg}$ and $20 \mathrm{~mm}$ depth was obtained out of the $4 \mathrm{~kg}$ metal charge that was put into the copper mold.

\section{Experimental Procedure}

Electrolytic iron and chromium were heated first by blowing the argon plasma jet onto the metal. As the metal began to melt, the hydrogen-argon gas mixture was used in place of argon for possible removal of impurities in metal. When the metal was perfectly melted and the desired temperature reached, the initial concentrations of carbon and nitrogen were adjusted by adding graphite powders while stirring the melt mechanically or by blowing nitrogen gas onto the melt.

Immediately after this treatment, the decarburization or the denitrogenization was started with the plasma jet of hydrogen-argon gas mixture of a given composition. The flow rate of the gas was fixed at $8 \mathrm{l} / \mathrm{min}$, and the partial pressure of hydrogen was varied from 0.052 to $0.8 \mathrm{~atm}$.

The operational conditions at various hydrogen partial pressures are presented in Table 1 with the indicated temperatures. The power necessary to maintain the $1 \mathrm{~kg}$ metal pool out of $4 \mathrm{~kg}$ in the copper mold was 80 to $100 \mathrm{~V}$ and 300 to $400 \mathrm{~A}$. When the plasma jet was impinged on the melt, a cavity of about $5 \mathrm{~mm}$ deep and $10 \mathrm{~mm}$ wide appeared at the impingement point, and it was observed that the melt was fairly well stirred.

For the chemical analysis a 10 to $20 \mathrm{~g}$ metal was taken by sucking into a quartz tube. Carbon and nitrogen in metal were determined by the coulometric titration method and the Kjeldahl method, respectively. The accuracies of analysis were within $\pm 6 \mathrm{ppm}$ for carbon and $\pm 7 \mathrm{ppm}$ for nitrogen.

\section{Experimental Result}

\section{Decarburization by $\mathrm{H}_{2}-$ Ar Plasma Jet}

The results of decarburization of iron in the mag-

Table 1. Operating conditions of plasma jet at various hydrogen partial pressures and temperatures of molten iron

\begin{tabular}{lcccc}
$\begin{array}{c}p_{\mathrm{H}_{2}} \\
(\mathrm{~atm})\end{array}$ & $\begin{array}{c}\text { Voltage } \\
(\mathrm{V})\end{array}$ & $\begin{array}{c}\text { Current } \\
(\mathrm{A})\end{array}$ & $\begin{array}{c}\text { Output } \\
(\mathrm{kVA})\end{array}$ & $\begin{array}{c}\text { Temperature } \\
\left({ }^{\circ} \mathrm{C}\right)\end{array}$ \\
\hline 0.1 & 68 & 180 & 12.2 & 1650 \\
0.2 & 70 & 200 & 14.0 & 1660 \\
0.35 & 76 & 250 & 19.0 & 1590 \\
0.5 & 84 & 190 & 16.0 & 1670 \\
0.65 & 90 & 220 & 19.8 & 1620 \\
0.8 & 78 & 280 & 21.8 & 1640
\end{tabular}

nesia crucible are shown in Fig. 2 for various hydrogen partial pressures. The weight of melts was $3 \mathrm{~kg}$ except for $p_{\mathrm{H}_{2}}=0.5 \mathrm{~atm}$ where it was $3.6 \mathrm{~kg}$. The carbon concentration decreased from $0.5 \%$ to $0.1 \%$ within $20 \mathrm{~min}$ at $p_{\mathrm{H}_{2}}=0.8$ and $0.65 \mathrm{~atm}$, while $70 \mathrm{~min}$ were needed to decarburize from $0.3 \%$ to $0.1 \%$ at $0.1 \mathrm{~atm}$. The rate increased with increasing hydrogen partial pressure, and for each hydrogen partial pressure it remained constant regardless of the carbon concentration in high carbon range but decreased gradually below about $0.3 \%$ carbon.

Figure 3 shows the results of 18-8 stainless steel at different hydrogen partial pressures. A $3 \mathrm{~kg}$ metal was melted in the magnesia crucible and the temperature was about $1700^{\circ} \mathrm{C}$. The rate was independent of the hydrogen partial pressure, and the carbon in metal was lowered from $0.15 \%$ to $0.002 \%$ within $100 \mathrm{~min}$.

The results for $60 \% \mathrm{Cr}-\mathrm{Fe}$ alloys at different partial pressures are shown in Fig. 4 at about $1750^{\circ} \mathrm{C}$. Carbon decreased irrespective of the hydrogen par-

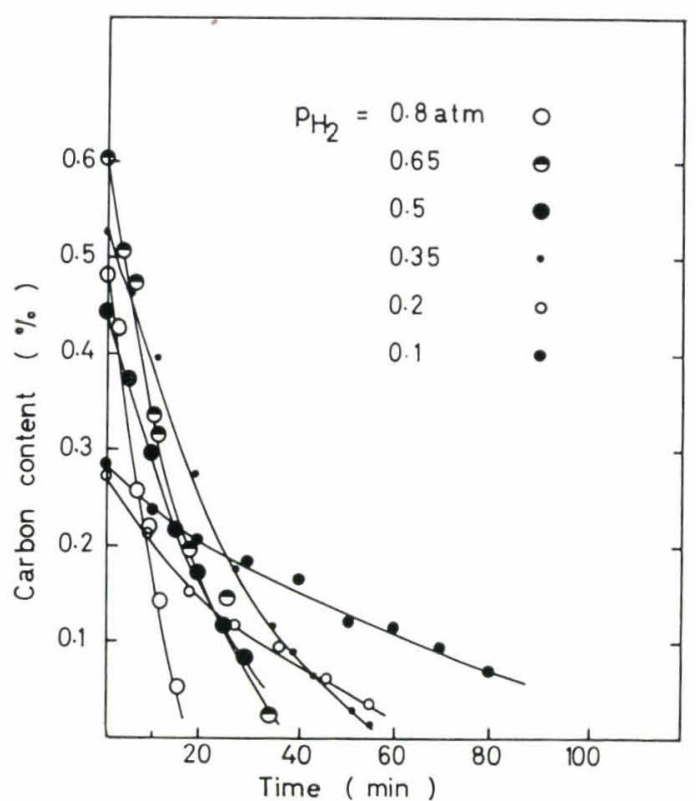

Fig. 2. Decarburization curves of iron by hydrogen-argon plasma with various partial pressures

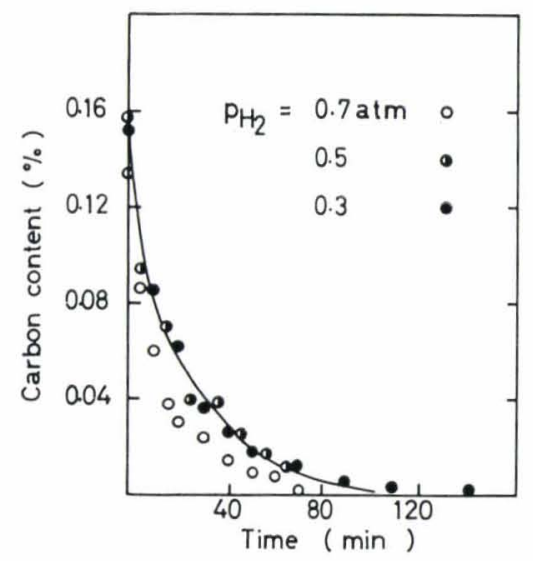

Fig. 3. Decarburization behaviors of 18-8 stainless steel by hydrogen-argon plasma 
tial pressure from $0.08 \%$ to $0.002 \%$ within $130 \mathrm{~min}$. The rate was comparatively smaller than the case of 18-8 stainless steel.

The electrolytic chromium $(\underline{\mathrm{C}}=0.007 \%)$ was decarburized at $p_{\mathrm{H}_{2}}=0.75$ atm using the water-cooled copper mold. An electric power of $87 \mathrm{~V}$ and $355 \mathrm{~A}$ was supplied to the metal, producing $1 \mathrm{~kg}$ melt pool out of $4 \mathrm{~kg}$. The carbon content of the melt decreased to $0.004 \%$ after $10 \mathrm{~min}$ and to $0.002 \%$ after $30 \mathrm{~min}$.

\section{Denitrogenization by $\mathrm{H}_{2}-\mathrm{Ar}$ Plasma Jet}

The denitrogenization behaviors of iron melted in the magnesia crucible are shown in Fig. 5 for various hydrogen partial pressures. The weight of melt was $2 \mathrm{~kg}$ and the temperature was about $1600^{\circ} \mathrm{C}$. The denitrogenization proceeded even with a plain argon plasma jet, but it was accelerated with increasing hydrogen partial pressure and reached a constant beyond $0.1 \mathrm{~atm}$. The rate was also dependent on the nitrogen content of the melt. Nitrogen was removed from $0.04 \%$ to the final concentration of $0.005 \%$ within $10 \mathrm{~min}$. The result of the final concentration

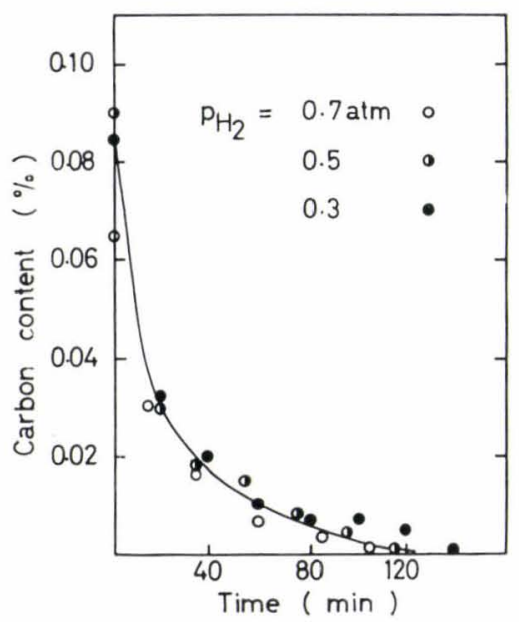

Fig. 4. Decarburization behaviors of $60^{\circ} \mathrm{Cr}-\mathrm{Fe}$ alloy by hydrogen-argon plasma

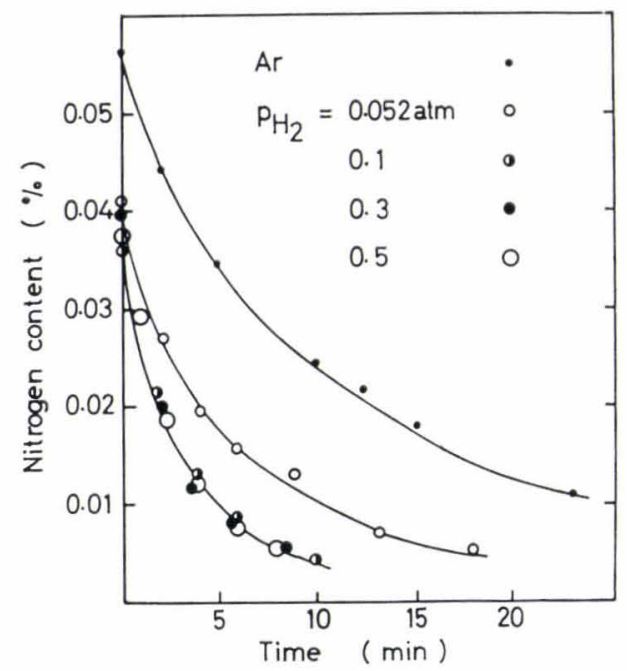

Fig. 5. Denitrogenization curves of iron by argon and hydrogen-argon plasmas with various partial pressures refined in the copper mold is presented in Table 2. Nitrogen was lowered from $0.005 \%$ to $0.0015 \%$ within $10 \mathrm{~min}$.

Figure 6 shows the results of $25 \% \mathrm{Cr}-\mathrm{Fe}$ alloy at different hydrogen partial pressures. The rate was independent of the hydrogen partial pressure, but dependent on the nitrogen concentration of the melt. Nitrogen was decreased from $0.04 \%$ to the final concentration of $0.011 \%$ within $20 \mathrm{~min}$. Taking account of the findings of Ban-ya, et al. ${ }^{6}$ ) that the denitrogenization did not proceed under flowing argon when the chromium content of alloy exceeded 12\% and also considering that the denitrogenization by the reaction of nitrogen in metal with molecular hydrogen is thermodynamically hard to proceed, the present results prove that hydrogen plasma effectively work for the denitrogenization of high chrcmium allcys. The result in the copper mold is also presented in Table 2: nitrogen was removed from $0.011 \%$ to $0.0065 \%$ within $40 \mathrm{~min}$.

In Fig. 7, the results of $60 \% \mathrm{Cr}-\mathrm{Fe}$ alloy melted in the magnesia crucible are shown for different hydrogen partial pressures. The rates were greatly dependent both on the hydrogen partial pressure and on the concentration of nitrogen. The time required to denitrogenize from $0.15 \%$ to the final concentration of $0.04 \%$ was $30 \mathrm{~min}$ at $p_{\mathrm{H}_{2}}=0.7 \mathrm{~atm}$, whereas $60 \mathrm{~min}$ was needed at $0.5 \mathrm{~atm}$.

\section{Decarburization by $\mathrm{CO}_{2}-\mathrm{Ar}$ Plasma Jet}

Iron of 720 or $840 \mathrm{~g}$ was melted at $1600^{\circ} \mathrm{C}$ in a magnesia crucible of $65 \mathrm{~mm}$ inner diameter. The oxidation of tungsten-cathode of the torch was so serious that the experiments at higher carbon-dioxide partial pressures were discontinued.

Table 2. The lowest nitrogen contents attained by hydrogen-argon plasma

\begin{tabular}{lcccc} 
& $\begin{array}{c}\mathrm{N}_{\text {lowest }} \\
(\mathrm{ppm})\end{array}$ & $\begin{array}{c}\mathrm{N}_{\text {initial }} \\
(\mathrm{ppm})\end{array}$ & $\begin{array}{c}\text { Refining } \\
\text { time }(\mathrm{min})\end{array}$ & $\begin{array}{c}p_{\mathrm{H}_{2}} \\
(\mathrm{~atm})\end{array}$ \\
\hline $\mathrm{Fe}$ & 15 & 50 & 10 & 0.75 \\
$\begin{array}{l}25 \% \mathrm{Cr} \\
\text { ferroalloy }\end{array}$ & 65 & 110 & 40 & 0.75
\end{tabular}

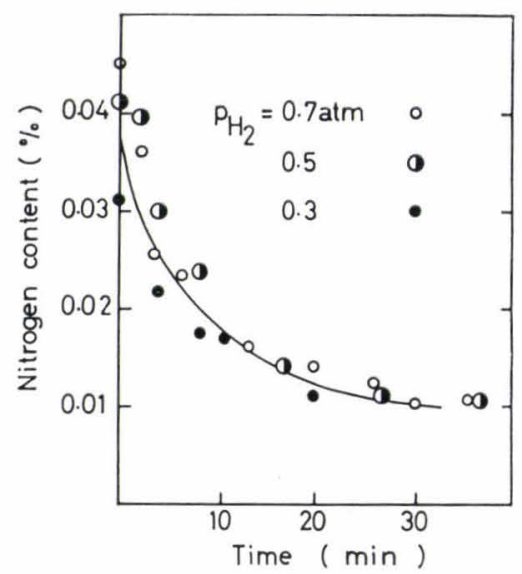

Fig. 6. Denitrogenization curve of $25 \% \mathrm{Cr}-\mathrm{Fe}$ alloy by hydrogen-argon plasma 


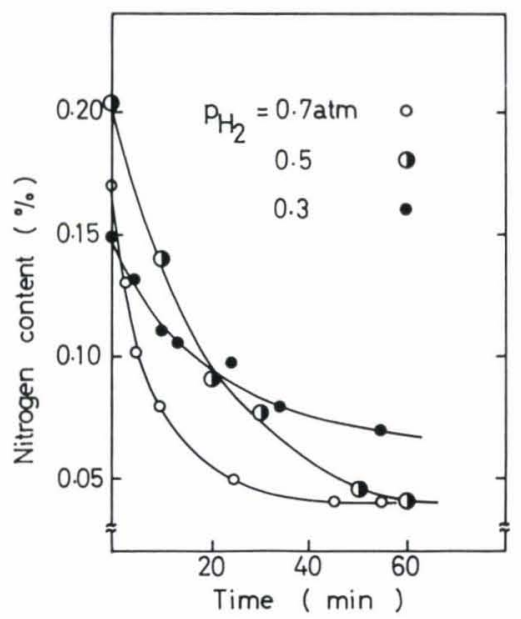

Fig. 7. Denitrogenization curves of $60 \% \mathrm{Cr}-\mathrm{Fe}$ alloy by hydrogen-argon plasma with various partial pressures

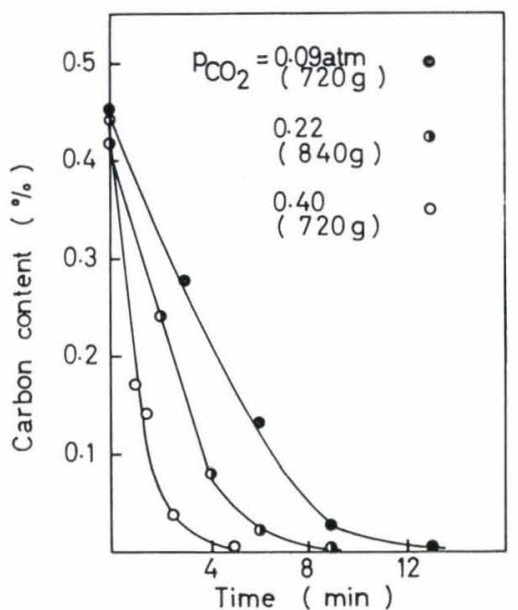

Fig. 8. Decarburization curves of iron by carbon-dioxideargon plasma with various partial pressures

The results are shown in Fig. 8 for different carbon-dioxide partial pressures. The decarburization rate is proportional to the partial pressure, and if the decarburization can be assumed to proceed by the chemical reaction $\mathrm{CO}_{2}+\underline{\mathrm{C}}=2 \mathrm{CO}$, the utilization efficiency of carbon-dioxide is $100 \%$ in the high carbon concentration range above $0.08 \%$.

\section{Discussion}

\section{Estimation of Reaction Products and Reaction Temper-} atures by Thermodynamic Consideration

When a hydrogen-argon gas mixture is ionized in the plasma jet, it reaches a temperature of higher than $10000^{\circ} \mathrm{C}$, when hydrogen exists as atom or ion. ${ }^{7)}$ However, when the jet is impinged on the melt surface, where the temperature is relatively low, it is unlikely that the hydrogen will reach the metal surface in the ionic state. At the interface of the melt, the temperature of gas drops rapidly and further, the positively charged ion will be repelled and neutralized by the metal which acts as an anode. Therefore, it must be considered that hydrogen will participate in

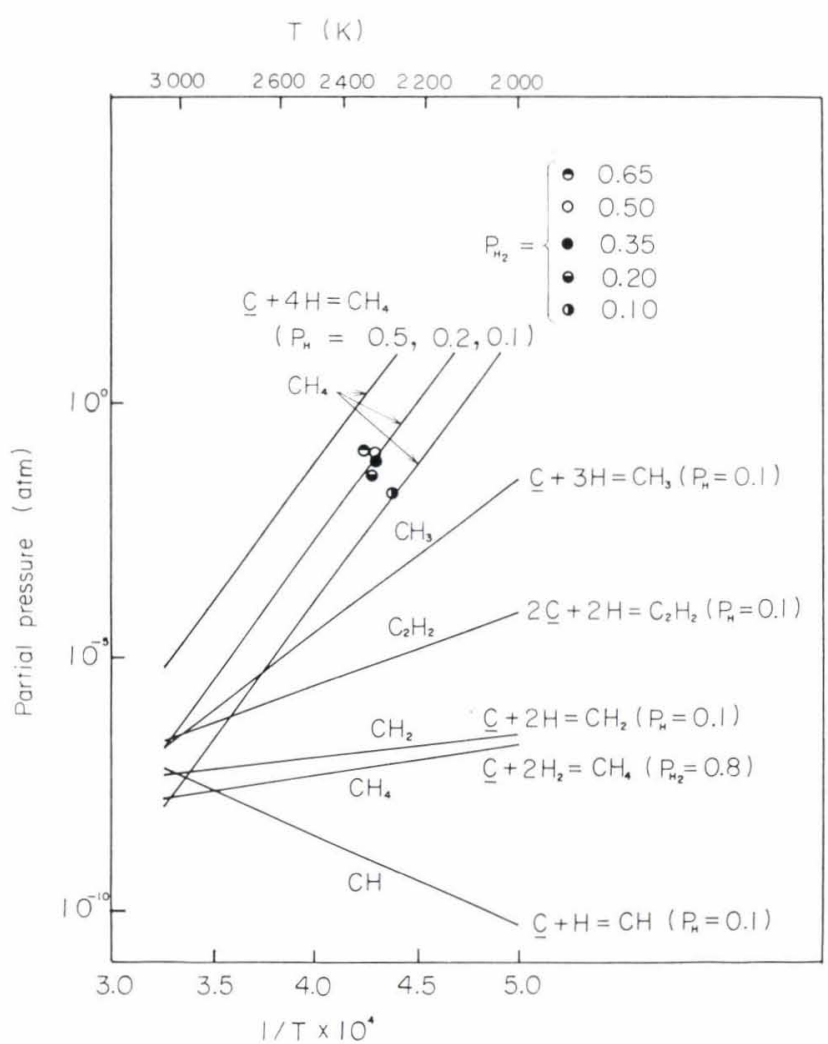

Fig. 9. Partial pressures of possible product gases on decarburization for $h_{\mathrm{C}}=0.2(0.2 \% \underline{\mathrm{C}}$ for iron $)$

the interfacial reaction as atom or molecule.

Provided that the atomic hydrogen participates in the reaction, the species of possible gaseous product of the decarburization must be such hydrocarbons as $\mathrm{CH}, \mathrm{CH}_{2}, \mathrm{CH}_{3}, \mathrm{CH}_{4}, \mathrm{C}_{2} \mathrm{H}_{2}$, etc. Figure 9 shows the relation between temperature and partial pressures of these gases with $p_{H}$ as a parameter, calculated on thermodynamic data for these reactions ${ }^{8,9)}$ with $h_{\mathrm{C}}=0.2(\underline{\mathrm{C}}=0.2 \%$ for iron $)$.

In the case of $p_{\mathrm{H}}=0.1 \mathrm{~atm}, \mathrm{CH}_{4}$ has the highest partial pressure below $2670 \mathrm{~K}$, and the partial pressures of $\mathrm{CH}_{3}, \mathrm{C}_{2} \mathrm{H}_{2}, \mathrm{CH}_{2}$ and $\mathrm{CH}$ decrease in this order. The ratio of $p_{\mathrm{CH}_{4}}$ to other molecules increases with increasing $p_{\mathrm{H}}$, and at $p_{\mathrm{H}}=0.9$ atm $p_{\mathrm{CH}_{4}}$ becomes the highest below $3000 \mathrm{~K}$. The partial pressure of $\mathrm{CH}_{4}$ calculated by assuming that carbon in metal should react with the molecular hydrogen is also shown in Fig. 9 for $p_{\mathrm{H}_{2}}=0.8 \mathrm{~atm}$. Obviously this partial pressure is far lower than the pressures which are calculated on the basis of atomic hydrogen.

The circular marks in Fig. 9 are the partial pressures of product gas estimated from the measured decarburization rate using the following equation:

$$
p_{\mathrm{CH}_{4}}=(d \underline{\mathrm{C}} / d t) \cdot(22400 / Q) \cdot(T / 273)
$$

assuming a molecule of product gas has one carbon atom, where $d \underline{\mathrm{G}} / d t(\mathrm{~mol} / \mathrm{min})$ is the measured decarburization rate, $Q(8000 \mathrm{cc} / \mathrm{min})$ is the gas flow rate, $T=300 \mathrm{~K}$ and at $\underline{\mathrm{C}}=0.2 \%$. These values are never lower than the actual partial pressures at the metal interface. In plotting the marks in Fig. 9, the hydrogen partial pressures at the reaction interface $p_{\mathrm{H}}^{*}$ 
are assumed to be $p_{\mathrm{H}}^{\circ}-4 p_{\mathrm{CH}_{4}}$, where $p_{\mathrm{H}}^{\circ}$ is the partial pressure which fully dissociated hydrogens would have under the total pressure of $1 \mathrm{~atm}$.

Naturally the actual $p_{\mathrm{H}}$ would be lower owing to the partial recombination of hydrogen atoms, and so the temperature be lower than that estimated above. In other words, the temperature of 2300 to $2350 \mathrm{~K}$ should be regarded as the maximum estimation. Further, because the temperature of the cavity on the melt surface right under the jet is probably higher than this estimation, this temperature should be interpreted as the mean temperature of the whole reaction zone including the cavity. Thus the estimated mean temperature, i.e., that which does not exceed $2350 \mathrm{~K}$, seems not very wrong from the observation that the melt never boils even at the plasma impingement area.

From the discussions stated above, it will be safe to say that the reactant gas is not hydrogen molecules but atoms. This means that hydrogen atoms in the plasma react directly with carbon in metal, freezing the recombination reaction $2 \mathrm{H} \rightarrow \mathrm{H}_{2}$. The main product species is most possibly $\mathrm{CH}_{4}$, though it will depend on the hydrogen partial pressure and the reaction temperature. No confirmation of this by gas analysis was attempted in the present research, however, because $\mathrm{CH}_{4}$ being more stable at lower temperatures, the gas composition would have inevitably changed during cooling. It would appear, therefore, that, at the present time at least, because of the limitations of experimental technique, the thermodynamic estimations should give more precise and reliable information on the plasma reactions.

The thermodynamic calculations for denitrogenization was made similarly to decarburization as presented in Fig. 10. Among the possible gaseous products of $\mathrm{NH}, \mathrm{NH}_{2}$ and $\mathrm{NH}_{3}$, the species which shows the highest partial pressure is $\mathrm{NH}_{3}$ under any condition. However, in this case, attentions must be paid to the formation of molecular nitrogen $\left(2 \underline{N}=\mathrm{N}_{2}\right)$ which is also possible to occur. The calculated partial pressures of the nitrogen molecule are presented together in Fig. 10 .

Comparing the partial pressures of each molecule in this figure, the relation $p_{\mathrm{N}_{2}}>p_{\mathrm{NH}_{3}}$ holds above $2100 \mathrm{~K}$ at $p_{\mathrm{H}}=0.1 \mathrm{~atm}$ and above $2400 \mathrm{~K}$ at $p_{\mathrm{H}}=0.5$ atm, both for $h_{\underline{\underline{N}}}=0.02$ ( $\underline{\mathrm{N}}=0.02 \%$ for iron). Thus, it is apparent that the main product for iron is the molecule $\mathrm{N}_{2}$ near the jet impingement area, and the formation of $\mathrm{NH}_{3}$ contributes slightly to denitrogenization as $p_{\mathrm{H}}$ increases.

On the melt surface apart from the plasma impinging spot, on the other hand, it is reasonable that hydrogen atoms should no longer be dissociated but are recombined to molecules, so that nitrogen is removed as $\mathrm{N}_{2}$ as the usual denitrogenization under inert gases. Consequently, the condition to form $\mathrm{NH}_{3}$ is not satisfied.

As for the case of $60 \% \mathrm{Cr}-\mathrm{Fe}$ alloy, the relation $p_{\mathrm{NH}_{3}}>p_{\mathrm{N}_{2}}$ below $2200 \mathrm{~K}$ at $p_{\mathrm{H}}=0.1$ atm and below $2530 \mathrm{~K}$ at $0.5 \mathrm{~atm}$, both for $h_{\underline{N}}=0.002$ ( $\underline{\mathbf{N}}=0.1 \%$ for

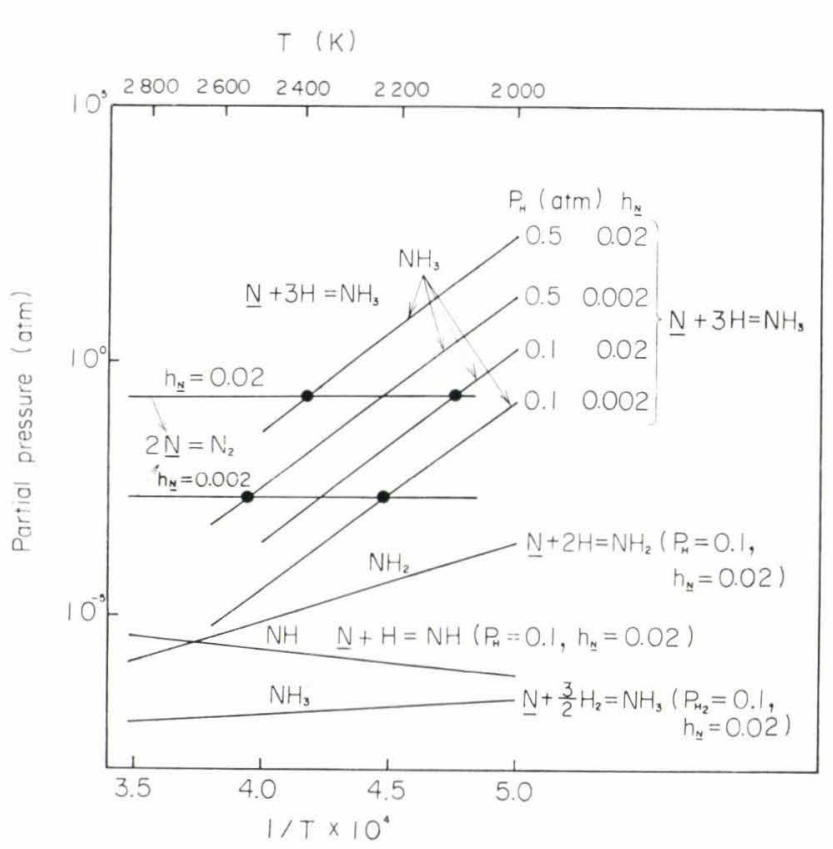

Fig. 10. Partial pressures of possible product gases on denitrogenization for $h_{\underline{\underline{N}}}=0.02(0.02 \% \underline{\underline{N}}$ for iron $)$ and $0.002(0.1 \% \underline{\mathrm{N}}$ for $60 \% \mathrm{Cr}-\mathrm{Fe}$ alloy $)$

$60 \% \mathrm{Cr}-\mathrm{Fe}$ alloy), was obtained as shown in Fig. 10. This critical temperature becomes higher with increasing $p_{\mathrm{H}}$ and with decreasing $h_{\underline{N}}$. In view of the temperature of the plasma impingement spot of about 2400 to $2600 \mathrm{~K}$ estimated from the foregoing decarburization results and also by the fact that the denitrogenization does not occur under argon atmosphere, it is believed that only the formation of $\mathrm{NH}_{3}$ contributes to the denitrogenization of $60 \% \mathrm{Cr}-\mathrm{Fe}$ alloy.

In the case of $25 \% \mathrm{Cr}-\mathrm{Fe}$ alloy, both $\mathrm{N}_{2}$ and $\mathrm{NH}_{3}$ have the possibility to be the reaction products in the present condition of $h_{\underline{\underline{N}}}=0.004$ ( $\underline{\mathrm{N}}=0.04 \%$ for $25 \% \mathrm{Cr}$ Fe alloy).

\section{Discussion of Reaction Mechanism}

The following discussions of the reaction mechanism are restricted by lack of precise knowledge of the reaction interface, the reaction temperature and the degree of dissociation of hydrogen. In the present investigation of the plasma jet refining, further, strictly controlled experiments to elucidate the reaction mechanism could not be made because the proportion of hydrogen in the working gas could not be changed without changing the power consumption. Therefore, many of the numerical values used in calculations are necessarily assumed ones.

The gas-metal reaction is generally rate-controlled by one or combination of the steps of (1) mass transfer on the gas side, (2) chemical reaction and (3) mass transfer on the metal side. Of these steps, the step of chemical reaction including the recombination reaction of hydrogen atoms which are unstable at lower temperatures can be very fast at sufficiently high temperatures. Therefore, this step was left out of consideration unless it became indispensable in interpreting the results. 


\section{Reaction of Decarburization}

\section{(1) Decarburization of Iron}

(i) Mass Transfer on the Gaseous Side

From the results of the sublimation rate of naphthalene blown with nitrogen gas and subsequently of the combustion rate of graphite by $\mathrm{CO}_{2}$, Taniguchi, et al. ${ }^{10)}$ obtained empirical equations for the mass transfer rate of the gas jet. Their equations are modified and expressed by Eq. (1) for easier application to the present conditions.

$$
\begin{aligned}
S h= & (0.0537 \sim 0.0839) \cdot R e \cdot S c^{0.5} \\
& \cdot(r / d)^{-0.25} \cdot(H / d)^{-0.5} \quad \ldots \ldots \ldots
\end{aligned}
$$

where, $S h=(k d / D)$

$R e=(\rho u d) / \mu$

$S_{c}=(\mu / \rho D)$

$k$ : mass transfer coefficient $(\mathrm{cm} / \mathrm{sec})$

$D:$ diffusion coefficient $\left(\mathrm{cm}^{2} / \mathrm{sec}\right)$

$\mu$ : viscosity (poise)

$u$ : gas velocity $(\mathrm{cm} / \mathrm{sec})$

$\rho$ : density of the gas $\left(\mathrm{g} / \mathrm{cm}^{3}\right)$

$H$ : distance between nozzle tip and metal surface $(\mathrm{cm})$

$d$ : representative length, here, the nozzle diameter $(\mathrm{cm})$

$r$ : radius of the reaction zone of the melt $(\mathrm{cm})$

As the area of reaction is not known in the application of Eq. (1), the calculation was made with $r$ as a variable, and with $H=2.5 \mathrm{~cm}, d=0.5 \mathrm{~cm}, p_{\mathrm{H}_{2}}=0.5$ atm, the gas flow rate $8 \mathrm{l} / \mathrm{min}(300 \mathrm{~K})$ and $T=2400 \mathrm{~K}$. The hydrogen was assumed to be fully dissociated, and values of $p_{11}=0.66 \mathrm{~atm}$ and $\rho=1.17 \times 10^{-4} \mathrm{~g} / \mathrm{cm}^{3}$ were used. The diffusion coefficient $D=26.11 \mathrm{~cm}^{2} / \mathrm{sec}$ and the viscosity $\mu=9.28 \times 10^{-4}$ poise were used for $\mathrm{Ar}$ $\mathrm{H}_{2}$ system. The gas velocity $u$ is $6000 \mathrm{~cm} / \mathrm{sec}$. Substitution of above values into Eq. (1) yields:

$$
S h=(3.81 \sim 5.96) \cdot r^{-0.25}
$$

Then the quantity:

$$
\left.\dot{n}_{\mathrm{H}}=(0.106 \sim 0.0165) \cdot r^{1.75} \cdot\right\lrcorner p_{\mathrm{H}}
$$

gives the mass transfer rate $(\mathrm{mol} / \mathrm{sec})$ of hydrogen atoms to the reaction surface $\pi r^{2}$ (leaving the particulars of the shape of the cavity out of consideration for the time being).

For the estimation of $\Delta p_{\mathrm{H}}$ the relation:

$$
\begin{aligned}
\dot{n}_{\mathrm{H}} / \pi r^{2} & =\left(k_{\mathrm{H}} / R T\right) \Delta p_{\mathrm{H}}=4 \dot{n}_{\mathrm{CH}_{4}} / \pi r^{2} \\
& =4\left(k_{\mathrm{CH}_{4}} / R T\right) p_{\mathrm{CH}_{4}}^{*}=4 \dot{n}_{\underline{\mathrm{C}}} / \pi r^{2}
\end{aligned}
$$

( $k$ : mass transfer coefficient)

is used, and this yields an approximate expression:

$$
\Delta p_{\mathrm{H}}=4\left(k_{\mathrm{CH}_{4}} / k_{\mathrm{H}}\right) p_{\mathrm{CH}_{4}}^{*}=4 p_{\mathrm{CH}_{4}}
$$

where, $p_{\mathrm{CH}_{4}}$ is the mean partial pressure of $\mathrm{CH}_{4}$ in the waste gas previously calculated in $V .1$. by the measured decarburization rate.

The calculation from the measured value of $\dot{n}_{\mathrm{C}}=$ $6.78 \times 10^{-3} \mathrm{~mol} / \mathrm{sec}$ using this relation gives a radius $r=1.1 \sim 1.5 \mathrm{~cm}$. The $r$, thus evaluated on the assumption that the rate-determining step be the mass transfer on the gaseous side, corresponds to the radius of the reaction zone, which is a little greater than 0.4 to 0.5 $\mathrm{cm}$ of the observed radius of the cavity formed by the plasma jet but far smaller than the crucible diameter of $4.25 \mathrm{~cm}$, indicating that the reaction does not occur over the whole melt surface but is limited to near the jet impingement area.

This is in accord with the fact that the temperature of the impingement area is much higher than the average melt temperature and can be around 2300 to $2350 \mathrm{~K}$ as is previously estimated. Besides, the finding that the decarburization rate at high carbon concentration is independent of the carbon concentration (Fig. 11) strongly suggests that the mass transfer on the gaseous side be the rate-determining step in the range of these concentrations, a conclusion which is consistent with the ordinary conventional decarburizations by $\mathrm{O}_{2}$ and $\mathrm{CO}_{2}$ gases.

(ii) Mass Transfer on the Metal Side

To estimate the strength of stirring by the plasma jet in comparison with the non-plasma gas flow, equations due to Davenport, et al. ${ }^{11}$ and to Matsushima and Mori, ${ }^{12)}$ as expressed by Eq. (2), are used.

$$
\dot{M} / \rho^{\prime} g H=\left(\pi / 2 \alpha K^{2}\right) \cdot(L / H) \cdot(1+L / H)
$$

where, $\dot{M}=(\pi / 4) \rho u^{2} d^{2}$ : the jet momentum per unit time $\left(\mathrm{g} \cdot \mathrm{cm} / \mathrm{sec}^{2}\right)$

$\rho^{\prime}$ : density of the melt $\left(\mathrm{g} / \mathrm{cm}^{3}\right)$

$g$ : gravitational acceleration $\left(\mathrm{cm} / \mathrm{sec}^{2}\right)$

$L$ : depth of cavity $(\mathrm{cm})$

$K$ : jet constant depending on $\operatorname{Re}$ and assumed to be $6.2^{12)}$

$\alpha$ : energy loss ratio related to the shape of the cavity and assumed to be $0.36^{12)}$

Using the values for the non-plasma gas flow at $p_{\mathrm{H}_{2}}=0.5 \mathrm{~atm}, \rho=1.17 \times 10^{-4} \mathrm{~g} / \mathrm{cm}^{3}, u=5.44 \times 10^{3} \mathrm{~cm} /$ sec, $d=0.5 \mathrm{~cm}, \rho^{\prime}=6.5 \mathrm{~g} / \mathrm{cm}^{3}$ and $H=2.5 \mathrm{~cm}$, the jet momentum $\dot{M}=6.78 \times 10^{2} \mathrm{~g} \cdot \mathrm{cm} / \mathrm{sec}^{2}$ and the depth of cavity for the non-plasma jet $L=0.14 \mathrm{~cm}$ are obtained. This calculated depth is consistent with the observation. The momentum of the plasma jet was found 4 times as great as for the non-plasma jet for the

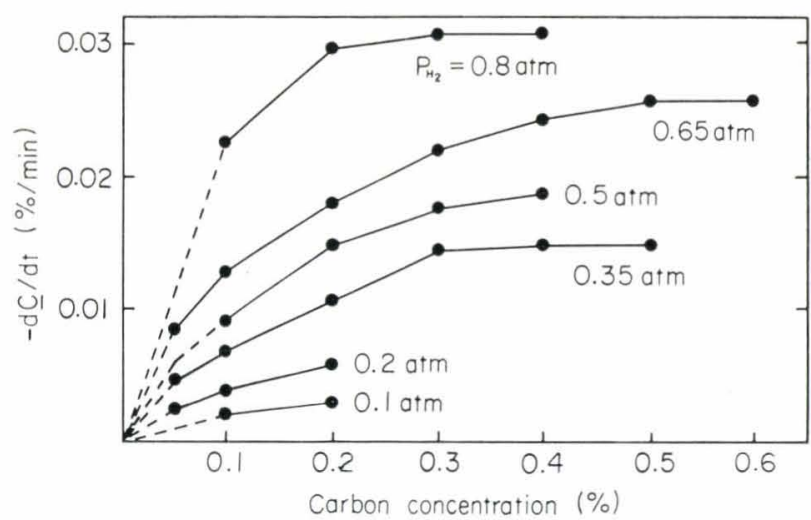

Fig. 11. Plots of the measured decarburization rates of iron against carbon concentration with various hydrogen partial pressures 
observed depth $L=0.5 \mathrm{~cm}$. This enhanced momentum is a measure of the stirring effect by plasma.

The following is an estimation of the decarburization rate, assuming the mass transfer of carbon in metal is the rate-determining step, by applying the rate equation of the oxygen mass transfer in metal, derived by Matsushima and Mori, ${ }^{12)}$ who blew the oxygen jet onto the molten silver. They gave the equation for the apparent mass transfer coefficient $k^{*}$ as:

$$
k^{*}=4.3 \cdot\left(L / R^{*}\right)^{2.5}
$$

where, $R^{*}$ is the radius at which the jet momentum is reduced to $1 \%$ of that at the center of metal surface and given as $R^{*}=1.07 \cdot K^{0.5} \cdot(H+L)$ with $K=6.2$. Then the decarburization rate $\dot{n}_{\underline{C}}(\mathrm{~mol} / \mathrm{sec})$ is expressed as:

$$
\dot{n}_{\underline{\mathrm{C}}}=\pi R^{* 2} \cdot k^{*} \cdot \Delta \underline{\mathrm{C}}=32.5 \cdot L^{2} \cdot(L /(H+L))^{0.5} \cdot \Delta \underline{\mathrm{C}} .
$$

where, $\Delta \underline{\mathrm{C}}$ is the concentration difference between the interface and the bulk $\left(\mathrm{mol} / \mathrm{cm}^{3}\right)$, and the reaction sites are assumed to be confined to the cavity. These equations yield $R^{*}=0.52 \mathrm{~cm}$ using $H=2.5 \mathrm{~cm}$ and $L=0.5 \mathrm{~cm}$, and $\dot{n}_{\mathrm{C}}=7.2 \times 10^{-3} \mathrm{~mol} / \mathrm{sec}$ using $\underline{\mathrm{C}}=0.4 \%\left(2.2 \times 10^{-3} \mathrm{~mol} / \mathrm{cm}^{3}\right)$.

The calculated $n_{\underline{\mathrm{C}}}$ is larger than the maximum rate of $1.3 \times 10^{-3} \mathrm{~mol} / \mathrm{sec}$ at $p_{\mathrm{H}_{2}}=0.8 \mathrm{~atm}$. If $L=0.3 \mathrm{~cm}$, for an observation error is inevitable, $R^{*}=0.5 \mathrm{~cm}$ and $\dot{n}_{\mathrm{C}}=2.1 \times 10^{-3} \mathrm{~mol} / \mathrm{sec}$ are obtained, but the value for $\dot{n}_{\mathrm{C}}$ is still larger than the measured rate, even though $R^{*}$ is in accord with the observed radius $(0.5 \mathrm{~cm})$ of the cavity. However, the calculated value $\dot{n}_{\mathrm{C}}$ would become larger, if the area of reaction were to be considered to extend to outside of the cavity.

Here, it is to be remembered that in applying the Eq. (4) to the present experiment, there are at least two factors that should have been taken into consideration but were not. Namely, the first factor is that the Schmidt number for the iron system is about 10 times larger than the silver system, and this would correct the calculation positively. On the other hand, the second factor, which would negatively correct, is that the ratio of the crucible radius to the melt depth is about half of the silver system so that in the present experiments the stirring was relatively insufficient in the bottom part of the melt. Besides, the difference of gas momentum used between the present work and Matsushima and Mori's should be taken into account.

In the later stage of the reaction below $\underline{\mathrm{C}}=0.3 \%$, the decarburization rates are roughly proportional to the carbon concentration, so that Eq. (4) is applicable. It may safely be said then that the carbon mass transfer in metal takes part in the rate-determination in the low carbon range. However, the mass transfer in gaseous phase as mentioned above cannot be ignored because the dependence of the rate on hydrogen partial pressure was observed (Fig. 11). Accordingly, it is believed that the mass transfer in both gas and metal are important in the rate-determination of decarburization of the iron-carbon system.
(2) Decarburization of 18-8 Stainless Steel and $60 \% \mathrm{Cr}-\mathrm{Fe}$ Alloy

In case of 18-8 stainless steel, the mass transfer in metal may be the rate-determining step, since the decarburization rate is not dependent on the hydrogen partial pressure and the logarithm of the carbon content shows a linear relation to the refining time as illustrated in Fig. 12. The slope of the straight line is $0.017 \mathrm{~min}^{-1}$, which is considerably smaller than the calculated values of $0.054 \mathrm{~min}^{-1}(L=0.3 \mathrm{~cm})$ and $0.183 \mathrm{~min}^{-1}(L=0.5 \mathrm{~cm})$ using Eq. (4), probably by the reasons described above. The diffusion coefficient of carbon for the Fe-Cr system, as estimated from the data of the solids, ${ }^{13)}$ could be about $40 \%$ of that for iron. Consequently, the mass transfer of carbon for the $\mathrm{Fe}-\mathrm{Cr}-\mathrm{C}$ system is expected to be slower than for the $\mathrm{Fe}-\mathrm{Cr}$ system so that the contribution of the gaseous mass transfer may be negligible, contrary to the $\mathrm{Fe}-\mathrm{C}$ system.

The decarburization of $60 \% \mathrm{Cr}-\mathrm{Fe}$ alloy is similar to that of 18-8 stainless steel, but the slope of the straight line in Fig. 12 shows $0.012 \mathrm{~min}^{-1}$ which is yet smaller than the value for $18-8$ stainless steel due to decrease in the diffusion coefficient of carbon with increase in chromium content.

\section{Reaction of Denitrogenization}

(1) Denitrogenization of Iron

The reaction product of the denitrogenization of iron may be $\mathrm{N}_{2}$ as already discussed in V.1. The reaction rates increased with increasing hydrogen partial pressure until it reached 0.1 atm and remained constant beyond that pressure (Fig. 5). Moreover, the relation between the logarithm of nitrogen content and refining time is linear as shown in Fig. 12. These facts indicate that the denitrogenization in the present experiment was retarded by the adsorbates such as oxygen which is removed as hydrogen partial

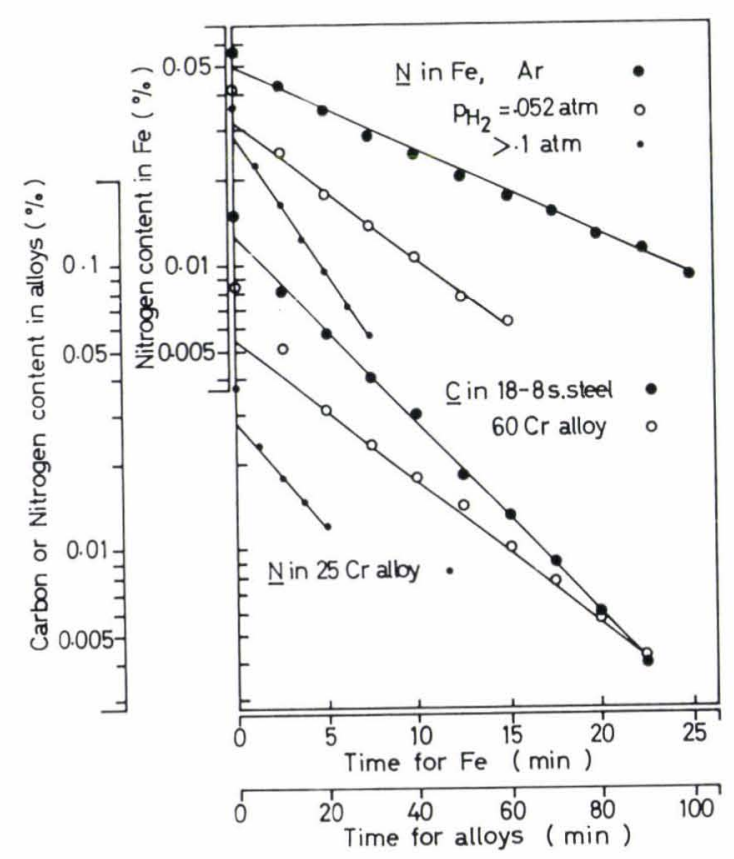

Fig. 12. Logarithms of the carbon and nitrogen concentrations against the refining time 
pressure increases, and finally above $0.1 \mathrm{~atm}$, it is controlled only by the nitrogen mass transfer in metal.

The calculation of the denitrogenization rate by use of Eq. (4), confining the reaction site within the cavity, yields $0.081 \mathrm{~min}^{-1} \quad(L=0.3 \mathrm{~cm})$ and 0.275 $\min ^{-1}(L=0.5 \mathrm{~cm})$. These values are not far different from the measured value of $0.097 \mathrm{~min}^{-1}$ under conditions of $p_{\mathrm{H}_{2}}>0.1 \mathrm{~atm}$. But, if the reaction is taken to occur over the whole free surface of the melt, the rate constant, calculated on the basis of the formation of nitrogen molecules, becomes far larger than the measured.

\section{(2) Denitrogenization of $25 \% \mathrm{Cr}-\mathrm{Fe}$ Alloy}

The denitrogenization is independent of hydrogen partial pressure, and a linear relation between the logarithm of nitrogen content and refining time was obtained as shown in Fig. 12. The slope of the line is $0.018 \mathrm{~min}^{-1}$ which is smaller than that of iron, corresponding to the diffusion coefficient of nitrogen ${ }^{\mathbf{1 4}}$ ) lowered by an addition of chromium, e.g., while the diffusion coefficient of $25 \% \mathrm{Cr}-\mathrm{Fe}$ alloy is about one third of iron, the observed rate is a fifth.

Both $\mathrm{N}_{2}$ and $\mathrm{NH}_{3}$ are possible as a product, but regardless of the product species the mass transfer of nitrogen in metal was found to control the reaction rate.

(3) Denitrogenization of $60 \% \mathrm{Cr}-\mathrm{Fe}$ Alloy

As described in $V .1$., only $\mathrm{NH}_{3}$ is the possible reaction product gas for $60 \% \mathrm{Cr}-\mathrm{Fe}$ alloy. The reaction rates decreased further compared with that of $25 \%$ Cr-Fe alloy and showed again dependency on the hydrogen partial pressure (Fig. 7). The final nitrogen concentration was not lower than $0.04 \%$. The reaction rate calculated by Eq. (4), assuming the nitrogen concentration at the reaction interface $0.04 \%$ and taking account of nitrogen diffusion coefficient decrease, agrees fairly well with the measured value at $p_{\mathrm{H}_{2}}=0.5 \mathrm{~atm}$. The dependence of denitrogenization rates on the hydrogen partial pressure should be explained in such a manner that the higher $p_{\mathrm{H}}$ makes the concentration gradient for $\underline{\mathrm{N}}$ diffusion greater, lowering the nitrogen concentration at the reaction interface.

\section{Conclusion}

(1) The hydrogen-argon plasma jet is effective for decarburization and denitrogenization of iron and iron-chromium alloys; this leads to technical pos- sibility of the direct production of iron-chromium alloys from chromite ores.

(2) In the case of $25 \% \mathrm{Cr}-\mathrm{Fe}$ alloy, the final concentrations of carbon and nitrogen refined are $\underline{\mathrm{C}}<$ $0.002 \%$ and $\underline{\mathrm{N}}=0.0065 \%$, satisfying the requirements for good intergranular corrosion resistance and ductility.

(3) The reaction mechanisms of decarburization and denitrogenization are concluded as follows:

(i) The decarburization product is likely to be $\mathrm{CH}_{4}$ and the reaction is controlled by gaseous mass transfer in higher carbon concentrations and by metallic mass transfer in lower carbon concentrations for any metals studied in the present work.

(ii) The denitrogenization product is mostly $\mathrm{N}_{2}$ except for $60 \% \mathrm{Cr}-\mathrm{Fe}$ alloy in which $\mathrm{NH}_{3}$ should be the predominant species. The reaction for three metals studied is controlled by mass transfer of nitrogen in metal.

\section{REFERENCES}

1) N. N. Rykalin, A. A. Erokhin and O. G. Salieva: Proc. 4th ICVM, ISIJ, (1974), 139.

2) H. Tezuka, S. Sugiura and T. Sugiyama: Proc. 4th ICVM, ISIJ, (1974), 142.

3) F. Esser, H. Fiedler and W. Lachner: Proc. 4th ICVM, ISIJ, (1974), 145.

4) W. Lachner, H. Fiedler and F. Müller: Proc. 4th ICVM, ISIJ, (1974), 149.

5) J.J. Demo: Met. Trans., 5 (1974), 2253.

6) S. Ban-ya, T. Shinohara, H. Tozaki and T. Fuwa: Tetsuto-Hagané, 60 (1974), 1443.

7) Y. Hayakawa and O. Matsumoto: Plasma Chemistry and Its Application, Sho-ka-bo, Tokyo, (1971), 63.

8) JANAF Thermochemical Tables: 2nd Ed, Ed. by D. R. Stull and H. Prophet, National Bureau of Standard, Washington D.C., (1971).

9) Thermochemistry for Steelmaking, II, ed. by J. F. Elliott, M. Gleiser and V. Ramakrishna, Addison Wesley Pub., (1963), 496.

10) S. Taniguchi, J. Kikuchi and S. Maeda: Tetsu-to-Hagané, 60 (1974), S413.

11) W. G. Davenport, D. H. Wakelin and A. V. Bradshaw: Heat and Mass Transfer in Process Metallurgy, ed. by A. W. Hills, Inst. Min. Met., (1967), 228.

12) M. Matsushima and K. Mori: Tetsu-to-Hagané, 57 (1971), 1636.

13) M. Hartl and H. Weber: Arch. Eisenhüttenw., 43 (1972), 609.

14) K. David and J. A. Schuntz: Arch. Eisenhüttenw., 43 (1972), 215. 